\title{
SharePoint as enabler for collaboration and efficient project knowledge sharing
}

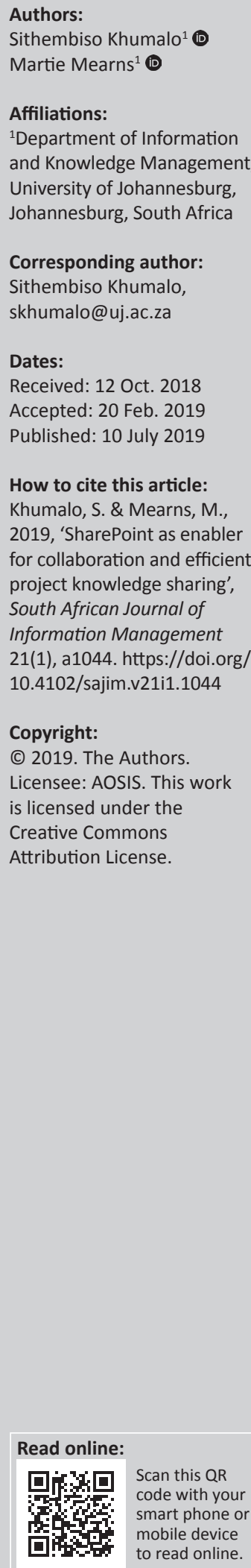

Background: Cutting-edge web technology applications have improved the manner in which business is conducted, allowing organisations to deliver business projects effectively. There is an untapped potential to power up SharePoint as a business application platform for content management, knowledge sharing and collaboration within organisations.

Objectives: The objectives of the study were to determine how SharePoint enables a retailer to share knowledge, collaborate and manage its content and to investigate the value brought by SharePoint to the organisation.

Methods: An interview schedule was used to collect data in order to help determine what the SharePoint users' needs are and whether they are being met using SharePoint. Two developers of SharePoint in the organisation and a further 10 users of SharePoint were selected to determine if the application of SharePoint is meeting the users' needs. The findings of the interview schedule were analysed through a descriptive content analysis with the support of Atlas.ti as a qualitative data analysis research tool.

Results: The research findings indicated that the platform does help employees in various ways, mostly enabling them to cut down on the time wasted in doing unnecessary tasks, such as manually creating projects by going to stores to collect performance reports. It also enabled the employees to effectively share business project reports and helped the organisations to project manage effectively.

Conclusion: SharePoint has benefited the retailer tremendously, ensuring improved productivity through real-time access to information as a result of improved collaboration and project-related knowledge sharing. Findings further indicate the need for knowledge management practices through the platform.

Keywords: Microsoft SharePoint; knowledge sharing; collaboration; content management; project management; retailer.

\section{Introduction}

Highly advanced web technology applications have enhanced the manner in which corporations conduct their day-to-day operations, allowing them to effectively and efficiently deliver businessrelated projects (Woodgate 2012:1). Web applications such as Microsoft SharePoint enable organisations to deliver business applications in an effective and appropriate manner (Hillier \& Pattison 2013:146). Microsoft classifies the web application as a critical business application that has the ability to perform and deliver cutting-edge business solutions (Goh, Ang \& Sikand 2003:161). The use of SharePoint as a critical business tool has the ability to enable organisations to effectively share knowledge, manage business documents and content, and collaborate during business projects (Herrera 2008:89). There is a need to power up and improve the use of SharePoint as a business application platform (Holliday et al. 2007:4). Thus, this study focused on determining how SharePoint enables a retailer to share knowledge, and collaborate and manage its content, and investigating the value brought by SharePoint to the organisation, and SharePoint as an enabler for collaboration and efficient project knowledge-sharing (Russell 2013:162).

The use of web technology applications is increasing within organisations, allowing companies to deliver their business needs effectively and efficiently. Many organisations are adapting the use of SharePoint as their primary intranet-enabled platform to collaborate and efficiently share project knowledge (Goh et al. 2003:161). According to Lindvall, Rus and Sinha (2003):

$[O]$ rganisations that use SharePoint effectively will be able to gain access to tacit and explicit knowledge of their employees and workflow will be enhanced, this will occur through features that allows collaboration and the development of new knowledge. (p. 138) 
Organisations such as EmpowerCS Consulting Services have been growing successfully using Microsoft SharePoint.

SharePoint monitors an organisation's ability to manage the time spent on projects; it also promotes collaboration that ensures the sharing of knowledge amongst employees about the projects in progress (Mckenna 2008:4). The use of SharePoint is growing in the business environment, allowing various companies to improve knowledge management and knowledge sharing (Herrera 2008:86). SharePoint users have access to business knowledge and insight (Scale 2009:12). This allows the creation of a workplace driven by best information-flow practices (Koplowitz \& Owens 2009:22).

The challenge is getting users to understand the value offered by the platform and learning how to efficiently collaborate more and share knowledge through the platform (Cisco 2011:2). As a result, many users find the platform too complex and they end up using it only as an information repository instead of realising its full potential. SharePoint is sometimes complex and does not accommodate users' skills, especially if the right training is not given. To minimise this challenge, it is important to develop certain strategies on how to better use SharePoint through a framework. Thus, it is significant to understand the role it plays in order to improve an organisation's performance through collaboration and knowledge sharing.

This article reports on research conducted to determine how the current use of Microsoft SharePoint at a major retailer, with its head office in South Africa, addresses the users' need for knowledge sharing, collaboration and content management (Krause et al. 2010:73). Previous research indicated that SharePoint has the potential to enable an organisation to improve their business operations if the business application platform is used effectively (Holliday et al. 2007:4). Therefore, the research project aimed to determine how effectively SharePoint is used within the retailer, what the users of SharePoint think about its use, whether it can be enhanced and what the unmet needs of users are. The objectives for this research were as follows:

- Objective 1: To determine how SharePoint enables the retailer to share knowledge, collaborate, and manage its documents and content.

- Objective 2: To investigate the value brought by SharePoint within the retailer.

\section{Research problem and objective}

The implementation of Microsoft SharePoint by the retailer is a clear indication that the organisation recognises and acknowledges the role of the web platform as a crucial business tool that can help it improve its business functions. The retailer needs to be able to ensure that Microsoft SharePoint meets its users' needs and that the web platform enables its employees to share knowledge, collaborate and manage content. The use of SharePoint by the retailer's employees has to be investigated in order to determine if the web platform meets their needs as users.
If the retailer fails to develop various knowledge management collaboration strategies in order to use SharePoint effectively or to recognise the vast capabilities of SharePoint, it will fail in ensuring the full exploitation of the web platform as a solution. This research aims to determine if SharePoint is effectively used within the retailer and if it is meeting the users' needs. This will determine the manner in which SharePoint should be used or enhanced to suit the retailer's SharePoint users' needs and the organisation as a whole. The main aim of this research is to determine how SharePoint can enable the retailer to improve knowledge sharing, collaboration and document management in order to effectively achieve organisational goals.

\section{Literature review}

Microsoft SharePoint as a web-based application has penetrated the corporate market. Over $78 \%$ of Fortune 500 companies are using SharePoint; this is a statement from Microsoft (Woodgate 2012:2). Many organisations today are using the platform for content and collaboration (Riley \& White 2013:4). It is also predicted that the usage rate of SharePoint is just the start. With $67 \%$ of corporate organisations considering SharePoint as a workflow platform, Microsoft is positioning the platform as a critical business application (Woodgate 2012:2).

SharePoint can be defined as a web-enabled application that is installed on Microsoft Windows servers and that can be accessed from different machines in the network through a web browser (Crane 2010:3). On the website, one can store different information, such as documents, emails and spreadsheets. It enables an individual to store business information including tasks, projects, calendars and more. It therefore acts as a central repository to store all business information (Crane 2010:3). SharePoint is an automated platform and technology system that has the ability to facilitate knowledge sharing, collaboration and content management (Sy 2012:4).

SharePoint has unique workflow features that are out-ofthe-box such as approval workflow and records routing; this workflow application installed in SharePoint enables the effective workflow within an organisation (Favre 2011:4). Ryan (2010:27) points out that there are many other benefits of using SharePoint as discussed in the next section.

\section{SharePoint as a collaborative platform for project management}

SharePoint plays a significant role in enabling an organisation to collaborate and manage business projects. Through project Dashboard, which is embedded within SharePoint as a tool, an organisation is able to get a clear picture of the implementation of projects and also view the progress of a project (Laahs, McKenna \& Vickers 2002:12). The platform enables the organisation to regulate, automate and control certain aspects of projects through alerts that 
are programmable. The platform, through the calendar feature, also enables the project team to share meetings and appointments.

Microsoft SharePoint has the ability to track a project's progress, improve productivity and streamline business activities (Millett et al. 2005:122). The platform allows an organisation to develop schedules, and improve communication and feedback on the projects. It also ensures that all projectrelated activities are monitored and controlled. The platform has the capability of informing project managers about a project's performance and possible execution dates (Sy 2010:4).

It is important to note that SharePoint enables an organisation to collaborate throughout the business processes. This can be achieved because the platform allows the organisation to manage the projects, tasks and the sharing of project and progress-related documents amongst different groups (Seven Technologies 2010:4). The SharePoint template enables an organisation to share content and knowledge about business activities (Bentley 2012:11). Through the platform, the organisation is able to assign and manage tasks to individuals in a group and track the availability of resources and the project's progress. The platform allows employees to report time spent on projects in the form of feedback (Seven Technologies 2010:2).

\section{Efficient project knowledge sharing through SharePoint}

Microsoft SharePoint is significant in enabling an organisation to efficiently share knowledge on projects and business as a whole. Tools such as Blogs and Wikis enable employees to participate in online discussions as a team (Williams 2011:76). These tools also ensure that employees receive daily updates and projects' progresses. Through these tools, employees are able to share skills and competencies that are related to projects they work on in order to improve the process, and this is a form of lessons-learned mechanism (Herrera 2008:86).

SharePoint Wiki tools play an important role in facilitating knowledge sharing for an organisation. SharePoint Wikis provide a conversational space for employees to share insights of work-related issues. These tools allow Internet chats, or messaging and video conferencing. The tools also improve productivity through enhanced collaboration and communication through a shared community space (Vasques \& Potter 2013:146).

\section{SharePoint for organisational content management}

SharePoint also has the ability to improve content or document management within an organisation. The platform allows users to work collaboratively on project documents and content. The document library feature within the platform allows individuals to not only see what content is modified in the document but also who modified the document
(Reed 2007:414). It also allows employees to check in and out of documents, so other users are informed (Herrera 2008:87).

The most important aspect of the SharePoint document library is the versioning option. It is important to review document versions when collaborating with team members. If changes are made on a document and an individual needs to change the content, SharePoint will save the documents separately, giving the opportunity to retain original versions and the newly modified document version (Herrera 2008:88).

Microsoft SharePoint has the ability to enable multiple users to work on the same document and content at the same time (Larrivee 2016:1). Through SharePoint one can also track changes that are made on a specific document (Larrivee 2016:1). The platform can improve content management as it enables the managers to give and/or restrict permission of documents or content from certain users, which means certain users must have permission to make changes in a document (Larrivee 2016:2).

\section{Research design and methods}

The purpose of this article is to report on how SharePoint enabled a retailer to collaborate and share project knowledge effectively and efficiently. The research investigated the value brought by SharePoint within the retailer and established the process for improving the use of SharePoint within the retailer. The ontological assumption for this research is interpretivism because of the approaches and strategies considered in order to effectively gather insight and understanding of SharePoint through the perspective of the retailer's users (Gerring 2003:08). This research used qualitative research approaches to gain insight into how SharePoint enables collaboration and the sharing of project knowledge in order to effectively achieve organisational goals (Carson et al. 2001:42). An inductive approach was used for this research study, along with evaluation research as a strategy; this is because of the fact that the research aimed at observing how SharePoint was used within the retailer in order to determine if it is meeting the users' needs with regard to project knowledge sharing and collaboration.

The data were collected through interview schedules using semi-structured questions during face-to-face interviews (Anderson 2006:23). Interviews were chosen to collect indepth data and insight from the users and developers of SharePoint within the retailer. Member checking was used to verify the validity and reliability of the data collected (Harper \& Cole 2012:510) after all interviews were completed and the collected data were collated. The interview schedule was created based on the research objectives one and two; two types of schedules were created: one was for the developers in order to determine if the platform was developed based the users' needs and the other interview schedule was for the users in order to determine if the implementation of SharePoint was meeting their needs. The schedules were created by the researcher with the assistance of the supervisor. Participants were active SharePoint users 
and individuals who develop SharePoint in the organisation. Permission was sought from the retailer to conduct 50 questionnaires with 10 follow-up interviews. However, permission was granted for only 10 interviews of SharePoint users within the retailer and two developers. Two different interview schedules were developed to obtain in-depth insight from the developers and the users. Thus, purposive sampling was used to focus on the accurate selection of the right informants for the research (Dolores \& Tongco 2007:147), in a deliberate attempt using a thoughtful choice of informants suitable for the research project (Bernard 2002:8).

The research questions, which also translated into questions that were asked to the research participants, included:

- How is SharePoint used within the retailer and if it is meeting the users' needs?

- How does SharePoint help the retailer to share knowledge for improved collaboration?

- What are the benefits of using SharePoint for managing project-related knowledge, documents and content?

- How effective is SharePoint in enabling the retailer to execute their corporate projects?

- What recommendations can be made to improve the implementation and the use of SharePoint within the retailer?

In order to comply with ethical research, permission was granted by the project manager by means of a signed permission letter. A letter of introduction and the informed consent were given to the research participants, in order to explain the research to the participants (Mertens 2010:12). The research participants were mostly managers of different divisions within the retailer; and interviews were conducted with a SharePoint leader, two software developers, four project managers, staff and the planning manager, the human resource systems manager, the area manager for scheduling, an information consultant and a business integration manager.

The data were analysed through descriptive content analysis. To support the analysis and interpretation of the data, Atlas.ti was used to conduct a qualitative descriptive content analysis. The recorded interviews were first transcribed into Microsoft Word documents, converted into PDF files and uploaded into Atlas.ti. The major themes were highlighted from the interviews in order to determine the relevant findings based on the research objectives. The themes emerged from the coding, which was uploaded into Atlas.ti. Codes were generated through the use of scheduling and some of the codes included 'aware of the knowledge-sharing capability', which referred to employees who were not aware of the knowledge-sharing capability of SharePoint. Another one included 'meeting needs in terms of collaboration', which referred to employees whose needs were met through SharePoint for collaboration.

\section{Ethical consideration}

In terms of the ethics and values of conducting research, formal permission to conduct the study was given by the retailer's project manager. The participants were informed about the nature of the research study and its intention. The participants' names were not revealed under any circumstances and participants consented to participate because of the academic nature of the study.

\section{Results and discussion}

The main objectives of the study were to investigate the value brought by SharePoint within the retailer; to determine how SharePoint enables the retailer to share knowledge, collaborate and manage its content or documents; and to establish the process for improving the use of SharePoint within the retailer.

\section{Usage of SharePoint within the retailer to meet users' needs}

Based on the findings of the research, the retailer's SharePoint users shared their experience about the intranet-enabled platform, how they use it within the organisation and if it is meeting their needs. It was found that various users utilise the platform for different purposes according to their line of work within the organisation. The retailer is an organisation that sells branded clothing footwear and textiles; they also sell stationery and houseware brands, so they deal more with reports and the sending and receiving of reports. Most users apply the platform to collaborate on business-related reports; they also use it for workflows, automated processes and to track the progress of store sales and projects. SharePoint users stated that they used the platform to extrapolate reports and give feedback to stakeholders and their business partners.

The employees of the retailer use the platform to draft various reports and to collaborate through those reports. Employees use the platform to keep track of the people they send to stores. For example, they used to send 20 people to collect information on stores and they have to email all those reports back to their manager. This means that the manager would have 20 different emails with 20 different reports, but because they use SharePoint to send all the reports in a shared space, the platform enables the users to work on the same document at once. The platform is also used to develop organisational websites and to maintain them. Some of the retailers' employees use SharePoint to build reports quickly and efficiently. For example, the majority of the research participants indicated that employees used to physically go to stores every day to gather information about the sales and progress of the stores, but now all reports are automated through the use of SharePoint.

Project management is one of the functions the employees use the platform for, and they normally set various team calendars, thus allowing all individuals working on a project to add their information on the platform in order to track their daily progress. The platform has cut down communication by email and allows employees to communicate through the platform. 
Below are some of the direct quotes taken from the research interviews on whether SharePoint meets their needs as users:

'I think [SharePoint is] very effective especially [since] we've begun a new way of work here, where we [are] trying to streamline our activities [to] cut down [on time] ... [What] would have taken a user ten minute[s] to find they now [find] within a couple of seconds. So that [gives] us some productivity, stopping emailing, silly calendars on [Microsoft] Excel.' (Participant 1, male, Projector Manager)

The research participants indicated that in the absence of a proper calendar management tool in the past, they had little choice but to use Excel for that purpose. Employees also lacked skill to use Microsoft Outlook adequately, but because having been trained to use SharePoint properly it has significantly reduced the number of emails it would take to accomplish a specific task:

'There's no sending back-and-forth emails. Previously twenty people would send to one secretary, one secretary would open the email of twenty different spreadsheets, copy and paste ... it would take them couple of hours to do whatever it was, now doing it in a couple of minutes. So in terms of efficiency and productivity, putting everything in one place it's already helped us achieve something.' (Participant 1, male, Projector Manager)

Another participant agrees that needs are met:

'Obviously it's a central point, we don't have to distribute reports via emails. You don't have to wait for that email. You usually just subscribe to a report or one of the documents on the site and whenever an update comes through, [users] will get it.' (Participant 2, male, Human Resources Systems Manager)

Research participants recognise SharePoint as being effective in meeting their content sharing needs, as seen by this response from Participant 3 :

'For me if I think back on how we did things in the past, information sharing is quicker, a lot of our meetings start at eight or nine and in the past we had to wait for the information and the meetings would be based on previous weeks' information because it wasn't available at that stage. So now with SharePoint you can click you, got your information straight away.' (Participant 3, female, Area Manager for Scheduling)

Participant 3 also sees a time-saving benefit in SharePoint:

'[The] information sharing is great, it cuts my travelling time out for my guys, it cuts out office administrative issues. In [the] past my consultant would spend on average about eight hours a week gathering information just to go conduct an audit on a store, so that would now be eliminated. I actually did a time management study in my department and we spend on average three hours a day pulling reports for people so now that time can be used more productive[ly] somewhere else.' (Participant 3, female, Area Manager for Scheduling)

This participant therefore reports an average of 5 hours per day being saved as a result of SharePoint functionalities.

\section{Improved knowledge sharing and collaboration through SharePoint for the retailer}

The findings revealed mostly how users' document sharing needs have been met. However, with regard to knowledge sharing, the findings show that certain users agree that SharePoint enables them to share knowledge in the form of reports and communication about the work they do. Some users share knowledge through SharePoint by supplying information to one another through shared documents that contain significant knowledge or information related to the business. Other users state that the platform enables them to improve collaboration through the various documents they share and to create libraries that contain knowledge of the organisation that is of value to the organisation. However, there seems to be an unclear consensus on exactly what the knowledge sharing and collaboration capabilities on SharePoint at the retailer is.

According to the users, SharePoint allows them to work as teams and to share knowledge about the projects on which they are working, thus improving the collaboration aspect. It is important to note that some users responded that they hardly use the platform for knowledge sharing; rather, they mostly use it for collaborating through reports.

The retailer's SharePoint users relate the sharing of reports on which they work as part of sharing knowledge about business functions and SharePoint allows them to effectively create and share those reports. Users responded that SharePoint improves their collaboration, allowing them to create libraries within the platform. These libraries allow the users to store all business-related knowledge within the platform in order to ensure the effective access to the organisation's knowledge. Users also state that the platform has discussion forums and blogs that enable employees to ask questions related to the business when they do not understand as aspect of their work.

The discussion feature enables the users to share knowledge and promotes effective communication between various employees within the organisation. The discussion blogs are normally used to help users to work as teams and share business-related knowledge along the way. It is clear, however, that users utilise SharePoint for document management purposes, rather than to utilise knowledgesharing capabilities to its fullest extent. They do, however, apply it for knowledge-sharing purposes when they use it for reference, which enables them to improve future projects by extrapolating knowledge about how other projects in the past were conducted.

The confusion of what is meant by knowledge sharing is evident from Participant 3's answer regarding how SharePoint helps the retailer share knowledge through better collaboration. Her answer clearly relates to the SharePoint information management capabilities rather than knowledge sharing:

'I have consultants that do a lot of travelling and I can use the travelling schedule to see where they are. You can use it to gather information from different people, so you can load documents and request feedback and get it back. You can supply information to the entire company [at the push of a button]. If you want to see an area, you can type in the area and [the] information would appear. It's basically information 
sharing and it makes it easier on a smart phone just to access the link and you have got your information instead of going to five different routes just to get one answer.' (Participant 3, female, Area Manager for Scheduling)

This is a clear indication that SharePoint has the capability of performing knowledge management, but there is a lack of content owners. There should be people responsible for the management of content and knowledge within the platform in order to make better use of the platform in terms of knowledge sharing.

Although some of the retailers' SharePoint users are aware of the knowledge sharing for improved collaboration, this is a clear indication that the retailers' employees need to be capacitated to effectively apply the knowledge sharing and collaboration capabilities on SharePoint for its full potential to be reached.

The responses from Participants 3 and 8 show that they incorrectly equate the sharing of reports as knowledge sharing:

'SharePoint is relatively new to us. So what we are doing is we are putting all our daily reports onto SharePoint. We've also developed a few of our own reports on SharePoint, stuff that normally took us days to prepare ... we are using visual studio in connection with SharePoint to develop the reports and then we deploy it to SharePoint. So SharePoint to me is basically just the vessel, instead of us using the platform to manually build a report, then email the report, now its [an] automated report that can be accessed via SharePoint.' (Participant 8, male, Staff and Planning Manager)

'So I'm one of the builders for SharePoint ... that's what I use it for, I build reports for my staff and stores and all the different business partners, so they can access the site. But I access it myself for the reports I have created because it's automated and easy to go that route [compared to] the older route.' (Participant 3, female, Area Manager for Scheduling)

\section{The benefits of using SharePoint to share knowledge, collaborate, and manage project content and documents for retailer}

There are various benefits that come with the use of SharePoint, and this sub-question is aimed at understanding the manner in which the retailers' employees recognise the benefits of using the platform in meeting their business needs. According to the users, SharePoint enables them to build reports about the operational activities and collaborate on these reports. The platform enables the retailers' employees to access the information on their smartphones and this enables them to perform their work better, even when out of the office. It supports the information more effectively, and subsequently, the information-sharing process through the platform is quicker.

Users of the platform state that it helps them to work in teams when working on projects; they do not have to physically share reports of information but can easily exchange reports or edit the reports they are working on through the platform. Responses show that before the implementation of SharePoint, users used to take an average of 2 days to create reports, while it now only takes them an hour to finish compiling the same reports. They also state that before starting meetings about the performance of the stores, they used to wait for information to be collected, analysed and reported, and this resulted in the meetings being based on past redundant information. SharePoint has enabled users to base their meetings on real-time information, because current information about the daily activities and performance of the store is available. Participant 3 stated that 'I think it's having that information at your fingertips that is how beneficial the platform is to the user, enabling the effective sharing of business-related information'.

The platform has helped users to collect information quicker than before, when they used to physically go to stores in groups and collect information, an activity that could take up to a week to complete. This same informationcollection process now takes about an hour to collect via SharePoint. They are also able to inform the store manager about the percentage of the store performance in terms of sales. This in return ensures effective knowledge sharing and collaboration within the retailer. The platform also enables the users to be more collaborative in businessrelated projects, thus giving information to the members involved in the project about how far the project is. It helps users to track progress of projects and who has completed their parts of a project.

Users can furthermore streamline their activities, thus helping them cut down on doing unnecessary tasks. In terms of their stores and store management, users would search extensively for operational procedures, and it would take hours to find them. If they did not know what they were searching for, it would take them longer by telephoning and emailing people. The platform is now more intuitive, which means that information is always readily available. The platform has allowed users to make quicker decisions based on timely and accurate information about how much stores have sold and what orders are outstanding; this is available to users on predetermined reports.

SharePoint allows users at the retailer to create teams for learning, thus allowing them to learn and discuss the problems they face within the organisation. The quote from Participant 9 indicates how beneficial the implementation of SharePoint within the retailer has been:

'I think the business has now moved into the whole SharePoint idea, a lot $[o f]$ users have taken to it and they're using it more often. Especially with how we managing our projects like store openings, we do clothing sheets for stores, it's doing quite well.' (Participant 9, female, Information Consultant)

The platform tends to be used as a project management tool more often. Certain users stated that they use SharePoint to perform project management; it does the work well, as stated by Participant 6 : 
'And then in terms of projects management, it's serving its purpose to a certain extent for project management in IT within a certain functional area, but it's not used extensively throughout the business.' (Participant 6, male, Project Manager)

Participant 9 also recognised SharePoint project management capabilities:

'With projects, we are using it for tracking system, for new store openings. So in terms of building the new store right from there and all the internal operations right up until store opening.' (Participant 9, female, Information Consultant)

From what Participant 5 reported, the benefit of SharePoint as a mechanism to track projects and give feedback was clear:

'We use it for tracking projects, in terms of the workflows. So that we can track progress on projects. And then obviously also we extrapolate reports from it using the information on SharePoint so that we can give feedback to business in terms of where the problem is.' (Participant 5, male, Project Manager)

The platform supports the organisation's initiative to become more productive, to save time and money and to contribute its part towards ensuring that the organisation is able to achieve its goals and objectives.

\section{SharePoint efficiency in helping the retailer to execute their corporate projects}

When the users of SharePoint were asked whether the platform helps them to execute their corporate projects, seven of the interviewees stated that it did, with the exception of two interviewees and one being neutral. The platform is effective because it has cut down on the time spent on unnecessary tasks. Users stated that the platform was effective in helping them execute their projects faster as it enabled meeting deadlines on tasks assigned to them. When deadlines are overdue, the platform escalates the tasks to the manager, who can then immediately respond with reminders or corrective action.

\section{Participant 8 reports in this regard:}

'Very effective, [it] would take me about $30 \mathrm{~min}$, to prepare, or; I can go into SharePoint and it constantly updates itself on what is happening on the business.' (Participant 8 , male, Staff and Planning Manager)

Some users stated that the platform is effective in enabling them to gain a competitive advantage over other businesses. For example, the platform helps them to open stores in time in order to compete with other stores to get product to the market. One user stated that many of the retailers' stores always open late when new malls are opened, while other stores would open on time. The reason is because certain sections would not have items like cosmetics and there was always something missing. Since the implementation of SharePoint, it is easy to find out why and see if the situation can be remedied. Because the platform monitors the project, with information recorded into SharePoint every day of the project, it allows the organisation to open in time and enables it to remain competitive in this regard (Porter-Roth 2006:212).

Participant 5 reported as follows:

'Well, it's actually quite easy, because with SharePoint what we have done is, we wrote $[a]$ process. So every store has a process that they then convert to workflows, so the workflows are allocated at the beginning of a project to an individual, so there's one individual responsible for a task. Those tasks are then issued to them by email via SharePoint and once they have completed [the task] they need to confirm that they have done it or if they have not been able to complete the task they must put in [a] column [to notify us] that they didn't see what they were supposed to do and they couldn't do it. Also what it enables us to do is to put a central repository in terms of all the information [floor plans, documents and budgets]. So it's got one central point where we store everything, which makes it a lot easier for everybody. It's cut down dramatically on emails because every time you want to distribute a new floor plan, you had to email 60 to 70 people and now you upload it, send out a reminder saying that this [how it] is now being done and it's there for everybody to see. So from a project management point it is a workable tool, we are happy with it, it's made huge inroads into having the most updated information as well, everybody works with the same document. You don't have one person working on version A and another one on version B.' (Participant 5, male, Project Manager)

Participant 9 indicated the contribution of SharePoint in executing corporate projects towards getting products to the market. She refers to the fact that in the past when new malls opened, some stores would always be lagging behind other stores because of products not being on time. As SharePoint has been implemented, they can compete with their competitors by opening on time.

Participant 7 agreed that the platform supported him by saying:

'In my world it's helping me very much.' (Participant 7, male, Project Manager)

The fact that eight users believe that the platform is good for a sustainable competitive advantage, and only one user disagrees, indicates that the effectiveness of the platform in project execution is realised. It is clear that SharePoint is helping the organisation to gain a sustainable competitive advantage through improving project execution.

\section{Discussion}

The aim of this article was to find out how SharePoint can enable a retailer to improve knowledge sharing, collaboration and content management in order to effectively achieve organisational goals. It is important to note that the research intended to understand the users' perception on the implementation and use of SharePoint, in an attempt to understand the value of SharePoint. The first finding indicated that SharePoint allows users to effectively collaborate, share business reports and execute their projects. 


\section{Challenge 1: SharePoint enables the retailer to share knowledge, collaborate, and manage its documents and content}

The research findings showed that SharePoint is used within the retailer but not to its fullest capability. The findings indicated that the web-based platform is mainly used for collaboration and to share knowledge through various business-related reports. Users were asked what they used the platform for and the findings were that most users used the platform for collaboration by mainly sharing business reports. The platform enables the retailer employees to share business reports effectively, which in return improves collaboration on the projects. They use the platform in order to create reports and to share those reports with the key decision-makers within the organisation.

The findings also indicated that the platform is mainly used as a project management tool, which enables the users to keep track of the progress of projects the organisation is working on. The platform is mostly used as a central repository for all business-related information to be shared. Thus, the retailer's employees mainly use SharePoint as a content management platform. Because of knowledge sharing, the management of content and collaboration play an important role in an organisation. Thus, it is important for individuals to share business-related knowledge, to effectively manage businessrelated content and to collaborate in order to ensure that projects are effectively and efficiently completed.

\section{Challenge 2: SharePoint brings value within the retailer}

Even though knowledge sharing is not effectively practised through the platform within the retailer, the platform does meet certain business needs. The research indicated that SharePoint enables its users to cut down on the time wasted on unnecessary tasks. The platform makes it easy for users to carry out their projects by ensuring real-time access to business information and reports.

The research showed that even though some users do not fully understand the full capability of the platform, they still prefer using the platform. They all stated that the platform is consistently in line with the business strategy of the retailer, because the organisation is also aiming to cut down time wasted on unnecessary tasks and the organisation is also going paperless. Further findings indicated that users do believe that the platform is aligned with the retailers' business strategy as it enables them to effectively collaborate and execute projects. It also enables certain users to perform effectively and helps the retailer gain a sustainable competitive advantage. SharePoint helps the retailer to always keep track of the progress of projects and keeps track of what is needed to ensure the retailers' stores open on time, which helps the organisation to keep up with their competitors.

Based on the research findings, SharePoint brings value to the retailer by helping the organisation to share knowledge in the form of reports, to manage its business-related content and to collaborate on projects. This is a clear indication that SharePoint does play its part in helping employees execute their projects and achieve their business goals and objectives.

\section{Conclusion}

The Information and Communication Technology (ICT) age has brought significant changes in the manner in which corporations run their day-to-day business operations. Microsoft SharePoint is one of the applications that has developed from the ICT age and has improved the manner in which business is conducted. The web-enabled platform has enabled various organisations to effectively share knowledge, collaborate and manage their business content. A retailer has utilised the platform to its advantage in order run their dayto-day business. This is done through sharing project-related knowledge through the platform. The platform has also played a major role in enabling effective and efficient project management practice, which allows the retailer to effectively and efficiently deliver best business solutions. Through SharePoint, an organisation is able to effectively collaborate and manage organisational content, and improve decisionmaking. This article gave an overview on how SharePoint is used within a retailer. Significant findings articulated that the platform plays a very important role in ensuring that the retailers' employees collaborate effectively in their business projects.

The platform enables the retailer to share knowledge that is related to projects the organisation undertakes; according to the research participants, the platform has enabled the retailer to cut down on time spent creating and delivering store-related reports. The platform has also allowed the retailer to remain competitive with other stores, specifically when new malls open, as the platform allows the organisation to keep track of the various items that are and are not available. In conclusion, it is important to note that SharePoint has significantly enabled a retailer to effectively share business project reports, thus enhancing productively and business functions.

\section{Acknowledgements}

The authors would like to thank the IT Manager, Mr David Wilkinson, and the Business Integration Manager of the retailer, Miss Manthisana Mosese, for their support during the research study.

\section{Competing interests}

The authors declare that they have no financial or personal relationships that may have inappropriately influenced them in writing this article. The views and opinions expressed in this article are those of the authors and do not necessarily reflect the official policy or position of any affiliated agency of the authors. 


\section{Authors' contributions}

M.M. was responsible for the research design, methodology and supervision of the entire study including the literature review; and S.K. was responsible for the data collection, interpretation and writing the article.

\section{Funding}

This research received no specific grant from any funding agency in the public, commercial, or not-for-profit sectors.

\section{Data availability statement}

Data sharing is not applicable to this article as no new data were created or analysed in this study.

\section{Disclaimer}

The views and opinions expressed in this article are those of the authors and do not necessarily reflect the official policy or position of any affiliated agency of the author.

\section{References}

Anderson, J.D., 2006, Qualitative and quantitative research: There are numerous differences between qualitative and quantitative measurement, Imperial $\mathrm{COE}$, El Centro.

Bentley, J., 2012, Infuse SharePoint with content intelligence, Smartlogic, London.

Bernard, H.R., 2002, Research methods in anthropology: Qualitative and quantitative methods, AltaMira Press, Lanham, CA.

Carson, D., Gilmore, A., Perry, C. \& Gronhaung, K., 2001, Qualitative marketing research, SAGE Publications, London.

Cisco, 2011, Cisco unified computing systems: Meet the challenge of Microsoft SharePoint server workloads, White Paper, San Francisco, CA.

Crane, R., 2010, Getting started with SharePoint, Computer Information Agency, Beecroft.

Dolores, M.A. \& Tongco, C., 2007, 'Purposive sampling as a tool for informant selection', A Journal of Plants, People and Applied Research 10(5), 147-158.

Favre, C., 2011, SharePoint 2010 for project management, Pragmantic, Reston, VA.

Gerring, J., 2003, Interpretations of intepretivism, Boston University, Boston, MA.

Goh, D.H., Ang, R.P. \& Sikand, P., 2003, 'Building a portal reusable software components Singapore', Library and Information Systems Journal 37(3), 158-167. https://doi. org/10.1108/00330330310484369

Harper, M. \& Cole, P., 2012, 'Member checking: Can benefit be gained similar to group therapy?', The Qualitative Report Journal 17(2), 510-517.
Herrera, K., 2008, 'From static files to collaborative workspace with SharePoint', Library Hi Tech Journal 26(1), 80-94. https://doi.org/10.1108/07378830810857825

Hillier, S. \& Pattison, T., 2013, Microsoft SharePoint 2013 app development, O'Reilly Media, Sebastopol, CA.

Holliday, J., Alexander, J., Julian, J., Robillard, E., Schwartz, B., Ranlett, M. et al., 2007, Professional SharePoint 2007 development, Wiley Publishing, Indianapolis, IN.

Koplowitz, R. \& Owens, L., 2009, SharePoint: The backbone of your information architecture, KM World, Camden, ME, viewed 17 March 2014, from http:// edtc6320s12010team1.pbworks.com/f/SharePoint+as+the+backbone+of+your+inf oramtion+architecture.pdf.

Krause, J., Langhirt, C., Sterff, A., Pehlke, B. \& Doring, M., 2010, SharePoint 2010 as a development platform: Discover how SharePoint is a powerful foundation for building custom collaborative business applications, Apress, New York, NY.

Laahs, K., McKenna, E. \& Vickers, D., 2002, Microsoft SharePoint portal server: Building knowledge sharing applications, Digital Press, Daytona Beach, FL.

Larrivee, B., 2016, Industry watch: The impact of SharePoint 2016, AlIM International, Silver Spring, MD.

Lindvall, M., Rus, L. \& Sinha, S., 2003, 'Software systems support for knowledge management', Journal of Knowledge Management 7(5), 137-150. https://doi. org/10.1108/13673270310505449

Mckenna, F., 2008, SharePoint a primer: An overview for records, document and ECM managers, Knowledge Corporation, New York, NY.

Mertens, D.M., 2010, Research and evaluation in education and psychology, integrating diversity with quantitative, qualitative, and mixed methods: An introduction to research, SAGE Publications, Thousand Oaks, CA.

Millett, B., Te'o, T., Rhodes, D., Clarke, J. \& Carwell, S., 2005, SharePoint portal as a strategic management and planning tool: University of Southern Queensland
(USQ) as a case study, Forum of the Australasian Association for Institutional (USQ) as a case study, Forum
Research, Mandurama, NSW.

Porter-Roth, B., 2006, Applying electronic records management in the document management environment: An integrated approach, Xerox Corporation, Palo Alto, CA.

Reed, B., 2007, 'Electronic records management in Australia', Records Management Journal 7(3), 191-204. https://doi.org/10.1108/eb027111

Riley, C.D. \& White, S., 2013, Enterprise content management with Microsoft SharePoint, Microsoft Press, Washington, DC.

Russell, C., 2013, Connected value: The ROI benefits of business-critical SharePoint, Pique Solution, San Francisco, CA.

Ryan, D., 2010, 'What is the essence of records management?', Records Management Journal 20(1), 117-123.

Scale, M.S.E., 2009, 'Cloud computing and collaboration', Library Hi Tech News 9(10), 10-13. https://doi.org/10.1108/07419050911010741

Seven Technologies, 2010, SharePoint implementation: Enterprise project management and employee, Seven, Chicago, IL.

Sy, D.R., 2010, 7 ways to leverage SharePoint 2010 for project management successes, Innovative-e, Sterling Publishing, New York, NY.

Sy, D.R., 2012, SharePoint 2010 for projects management, O'Reilly, Sebastopol, CA.

Vasques, M. \& Potter, R.E., 2013, 'A (closer) look at collaboration using wikis', Journal of Applied Research in Higher 5(2), 145-155.

Williams, J.S., 2011, SharePoint site eases information flow for clinical engineering team, AIIM, MD.

Woodgate, I., 2012, The option for delivering business applications with SharePoint, PointBeyond Ltd, London. 